\title{
EDITORIAL
}

\section{Presenting the European Forum for TB Innovation: innovative thinking in progressing towards TB elimination in Europe}

\author{
Francesco Blasi*, Lee B. Reichman" and Giovanni Battista Migliori"
}

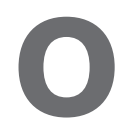

n March 9, 2012 the European Respiratory Society (ERS) launched its first ever think tank on tuberculosis (TB): the European Forum for TB Innovation. When we, as prospective authors, sat down to tackle the content layout of this short editorial, we realised that we could not just use the academic tone that commonly characterises scientific articles. The principles that have led the ERS to embrace the discussion surrounding TB innovation transcend science and academic discussion. They are principles originating from the need to rethink TB control in Europe and beyond. We therefore felt that our personal account on how we came to agree to contribute to this new initiative was the only acceptable way of bringing this editorial to life.

\section{FROM F. BLASI}

I will admit it. I am not a TB expert. I started my career as a cardiologist, to later embrace the field of respiratory care with a keen interest in pneumonia. I am, in other words, not a usual suspect. But even while immersed in my clinical practice in one of the major Italian cities, Milan, I was alarmed by the subtle and ominous presence of TB.

I am not referring to the persistent and tireless reminding by ERS colleagues from the TB Assembly, that TB is everywhere and well rooted among our population. That played a role, too. But my awakening came with the realisation that $\mathrm{TB}$ and multidrug-resistant (MDR)-TB in Europe, in Italy and in my city were and are besieging the life of the most vulnerable and anchoring their roots among the general population again [1-8]. Silently, but relentlessly.

The realisation that, in the 21st century, the tools to control the disease and alleviate patient suffering are still those described in the textbook I used throughout medical school has led me to commit to bring forward the agenda of TB control $[9,10]$ during my upcoming ERS presidency.

\footnotetext{
*Dipartimento Fisiopatologia Medico-Chirurgica e dei Trapianti, University of Milan, IRCCS Fondazione Cà Granda, Milan, and "WHO Collaborating Centre for TB and Lung Diseases, Fondazione S. Maugeri, Care and Research Institute, Tradate, Italy. ${ }^{~}$ Global Tuberculosis Institute, New Jersey Medical School, Newark, NJ, USA.
}

CORRESPONDENCE: G.B. Migliori, WHO Collaborating Centre for TB and Lung Diseases, Fondazione S. Maugeri, Care and Research Institute, Via Roncaccio 16, 21049 Tradate, Italy. E-mail: giovannibattista.migliori@fsm.it
The innovation agenda feels like the pivotal issue to finally tackle. The development of new tools and approaches for TB control can finally bring about the much-needed shake-up of the management of $\mathrm{TB}$, and it is time to recognise that innovation goes beyond the introduction of new technologies and drugs, and essentially requires a new mind frame in the fight against the disease.

There is no doubt that innovation requires discussion and will require confronting ourselves with controversial and opposing views on what should be done to curb the TB epidemic. I personally have many questions, as a TB outsider, that I would like to see tackled. Can we use better prevention in TB control? Can we focus on TB infection as much as we focus on active disease?

And that is how the idea of a think tank forum for TB came about: to provide an environment whereby $\mathrm{TB}$ experts can express themselves free from institutional and policy constraints, a forum whereby the formulation of the right questions is the main objective.

\section{FROM L.B. REICHMANN}

To use the tone of my co-author, I am a usual suspect. Nevertheless, I am keenly interested in exploring what new there is to say on TB.

When I was invited to co-chair the Forum, and to provide an unbiased overseas view to the European TB world, I accepted without hesitation. What brought me to embark on this cochairmanship was not the perspective of being able to lecture the "other side of the Atlantic" on TB control, but rather grasp the chance to bring expert opinion back to the TB discussion table. To discuss not what the evidence says but what the evidence does not say, to look for questions rather than for answers.

It is my latest encounter with a former Soviet Union country that confirmed some of the fears I had been keeping to myself on the future of TB control and the need for fresh discussion. In December 2011, I had the opportunity to visit Estonia to observe their programme and meet several patients. Estonia, as many know, is burdened, as much of Eastern Europe and former Soviet Union countries are, with a mind-boggling MDR-TB problem, caused by previously poor programmes, poor followup, poor adherence, lack of political will and numerous other problems [1-6]. 
What was observed in Estonia was truly eye opening. Dedicated professional staffs, innovative programmes and effective implementation of the Stop TB Strategy were seen to be an effective means of TB control; not only apparently putting a crimp into TB control, but also, possibly, MDR-TB rates. But tragically, MDR-TB persists in Estonia. Despite the near impeccable execution of the fundamentals of TB control, the end of the TB and MDR-TB epidemic is far from being declared.

The key issue that I observed was that each of the cases I met (and these represented a spectrum of severity and prognosis) were infected, often years ago, by a source case that was invariably a known MDR-TB case who did indeed receive appropriate treatment. So the tragedy that we see is that the transmission of MDR-TB occurs between close contacts prior to diagnosis, even in the face of effective treatment, just as we learned from Wallace Fox and Dennis Mitchinson and the British Medical Research Council 60 yrs ago [11, 12]. And so, even the best treatment, such as in Estonia, may not (or often is not) enough to stop transmission, and that is only because transmission occurs possibly long ago and certainly prior to diagnosis. This simple fact is known to all, and has been for decades, but for some reason, it doesn't enter into the equation of TB control or TB clinics in Europe and beyond. Perhaps it is time to consider the heresy of acting differently, as the European Union Standards for TB Care document suggests [13].

The pipeline of new tools and the venturing into a field of new approaches opens the door to finally upgrading TB control $[14,15]$. The Forum represent an opportunity to go beyond technical discussions on the so-called "new tools" for TB control and pose the question that can open a much-needed discussion on what is required to finally turn the tide.

\section{FROM G.B. MIGLIORI}

I am a usual suspect too. Having served as the secretary for several organisations in my own country, the International Union Against Tuberculosis and Lung Diseases, and the ERS, I am used to organising, suggesting, eliciting and pushing. When the ERS asked me to serve as the Forum Secretary, I accepted with enthusiasm. After many years spent travelling throughout Eastern Europe, Africa and Latin America, resistance to change is one of the enemies I am used to fighting, and I do think the Forum is well equipped to do so by allowing this group of experts to remove their institutional "jackets" and provide the necessary "out-of-the-box" thoughts that can stimulate bold innovation in TB control.

\section{ABOUT THE FORUM}

The Forum consists of TB experts from throughout Europe aimed at providing an interface for discussion and innovative thinking in the field of comprehensive TB control.

The current TB and MDR/extensively drug-resistant (XDR)-TB control situation represents an opportunity for refocusing and optimising control strategies. In particular, the introduction of new diagnostic tools that might enable a rapid identification of drug-resistant TB (MDR/XDR-TB), the shift towards active case finding, new control approaches and a promising TB drug pipeline allow for a positive outlook towards the future. Complementing the high-level policy work of the World Health Organization (WHO) and international agencies, the

\section{TABLE 1 Synopsis of the European Forum for TB Innovation series}

Addressing and preventing resistance: rational use of new diagnostics and drug regimens

Addressing TB prevention: is LTBI a programmatic component?

Community and patient participation in TB control, care and cure: from incidental activity to structural involvement

Moving from hospital to community TB care: challenges and opportunities for high-burden MDR-TB countries

TB: tuberculosis; LTBI: latent tuberculosis infection; MDR: multidrug-resistant

Forum intends to stimulate discussion on how to best take advantage of new opportunities and advances to improve TB control and eventually progress towards TB elimination.

The first face-to-face meeting of the Forum was held in Lausanne, Switzerland on March 9, 2012. Summarising the priorities for the Forum, it was generally agreed that the ERS and the Forum itself should go where no one has gone before. The work of the Forum should not aim to replicate the policy and science-oriented work of other groups and institutions. The group should adopt a thinking-out-of-the-box approach as a firm guiding principle. It was felt that, free from institutional and policy commitments, the Forum members have an opportunity to act as a think tank and provide much-needed stimuli and direction to TB control and management in Europe. The discussion has steered away from policy implications and implementation plans. Forum members felt emphatically that these areas remain the responsibility of well-recognised institutions, organisations and other TB stakeholders. In other words, the Forum has the role of considering and discussing the heresy of acting differently in tackling TB.

The views for the Forum are to be presented in the European Respiratory Journal with a series of Forum articles (table 1). The articles will tackle key elements of TB control (chosen by means of a Delphi process and the subsequent discussion by Forum members) and will commit to stimulate discussion and generate debate around the need to innovate TB control in the key areas represented by new drugs and regimens, treatment of latent infection, community involvement and models of TB care.

\section{SUPPORT STATEMENT}

The European Forum for TB Innovation is supported through an unrestricted grant from Otsuka SA (Geneva, Switzerland) to the ERS.

\section{STATEMENT OF INTEREST}

A statement of interest for all authors can be found at www.erj. ersjournals.com/site/misc/statements.xhtml

\section{ACKNOWLEDGEMENTS}

The authors would like to thank the commitment of the Forum members as well as representatives of the WHO, the Global Fund and the Asian Pacific Society of Respirology for their participation in the meeting.

The European Forum for TB Innovation members and observers are, in alphabetical order: A. Khan (Pakistan), F. Blasi (Italy), S. Borisov (Russia), J. Caminero (Spain), L. Cuevas (UK), M. Danilovits (Estonia), M. Dara (observer; Denmark), A. Detjen (USA), F. Drobniewski (UK), C. Erkens (the Netherlands), P. Gondrie (the Netherlands), E. Jaramillo (observer; Switzerland), C. Lange (Germany), R. Loddenkemper 
(Germany), D. Maher (observer; Switzerland), D. Manissero (Observer; Switzerland), G.B. Migliori (Italy), T. Mori (Japan), A. Mosneaga (Moldova), L.B. Reichmann (USA), P. Thorn (UK), C. Yu (invited guest; Philippines) and J.P. Zellweger (Switzerland). The opinion of the members and observers of the Forum represents their individual opinion and in no way should be interpreted as institutional endorsement of the ideas and concepts hereby expressed.

\section{REFERENCES}

1 Zignol M, van Gemert W, Falzon D, et al. Surveillance of antituberculosis drug resistance in the world: an updated analysis, 2007-2010. Bull World Health Organ 2012; 90: 111D-119D.

2 Skrahina A, Hurevich H, Zalutskaya A, et al. Alarming levels of drug-resistant tuberculosis in Belarus: results of a survey in Minsk. Eur Respir J 2012; 39: 1425-1431.

3 Leimane V, Dravniece G, Riekstina V, et al. Treatment outcome of multidrug/extensively drug-resistant tuberculosis in Latvia, 20002004. Eur Respir J 2010; 36: 584-593.

4 Floyd K, Hutubessy R, Kliiman K, et al. Cost and cost-effectiveness of multidrug-resistant tuberculosis treatment in Estonia and Russia. Eur Respir J 2012; 40: 133-142.

5 Migliori GB, Sotgiu G, Lange C, et al. Extensively drug-resistant tuberculosis: back to the future. Eur Respir J 2010; 36: 475-477.

6 Balabanova Y, Radiulyte B, Davidaviciene E, et al. Risk factors for drug-resistant tuberculosis patients in Lithuania, 2002-2008. Eur Respir J 2012; 39: 1266-12699.
7 Fattorini L, Migliori GB, Cassone A, et al. Proficiency testing of first- and second-line anti-tuberculosis drugs in Italy. Eur Respir J 2012; 39: 1263-1266.

8 Fattorini L, Mustazzolu A, Piccaro G, et al. Drug-resistant tuberculosis among foreign-born persons in Italy. Eur Respir J 2012; 40: 497-500.

9 Raviglione MC, Uplekar MW. WHO's new Stop TB Strategy. Lancet 2006; 367: 952-955.

10 Raviglione M, Marais B, Floyd K, et al. Scaling-up interventions to achieve global tuberculosis control: progress and new developments. Lancet 2012; 379: 1902-1913.

11 Fox W, Ellard GA, Mitchison DA. Studies on the treatment of tuberculosis undertaken by the British Medical Research Council tuberculosis units, 1946-1986, with relevant subsequent publications. Int J Tuberc Lung Dis 1999; 3: Suppl. 2, S231-S279.

12 Mitchison DA. The diagnosis and therapy of tuberculosis during the past 100 years. Am J RespirCrit Care Med 2005; 171: 699-706.

13 Migliori GB, Zellweger JP, Abubakar I, et al. European Union Standards for Tuberculosis Care. Eur Respir J 2012; 39: 807-819.

14 Broekmans JF, Migliori GB, Rieder HL, et al. European framework for tuberculosis control and elimination in countries with a low incidence. Recommendations of the World Health Organization (WHO), International Union Against Tuberculosis and Lung Disease (IUATLD) and Royal Netherlands Tuberculosis Association (KNCV) Working Group. Eur Respir J 2002; 19: 765-775.

15 Sterling TR, Villarino ME, Borisov AS, et al. Three months of rifapentine and isoniazid for latent tuberculosis infection. $N$ Engl J Med 2011; 365: 2155-2166. 